\title{
El Sincretismo: pedagogía y educación superior (Reseña de la EFP)
}

\author{
Syncretism: pedagogy and higher education (EFP Review)
}

\author{
Alejandra Paola Pérez González \\ ... La enorme máquina de la educación es rígida, endurecida, coriácea, burocratizada. \\ Muchos profesores están instalados en sus costumbres y sus soberanías disciplinarias. \\ Éstos, como decía Curien, son como los lobos \\ que orinan para marcar su territorio y muerden a aquellos que penetran en él. \\ Existe una resistencia obtusa, incluso entre espíritus refinados. \\ El desafío es invisible para ellos. (Morin, 2000: 130)
}

Problematizar la actualidad de la pedagogía y sus conexiones con la Educación Superior, nos cuestiona sobre varios asuntos, por ejemplo, la pregunta por el Maestro Universitario, el lugar de la pedagogía en la edificación de saberes, diálogos y conocimientos. Ello devino de la preocupación por la experiencia pedagógica, de la pregunta por el ser mismo y de la reflexión sobre los saberes que se construyen hoy en las aulas. De estas reflexiones, surge la Escuela de Formación Pedagógica como una oportunidad de autocrítica de los mismos profesores sobre sus propias prácticas.

Es por eso, que en el segundo semestre del año 2015 se inició, con la coordinación de la Escuela de Formación Pedagógica y el apoyo de la Vicerrectoría Académica de la Universidad Surcolombiana, el Seminario-Taller: Evaluación en la Educación Superior. Primeramente, se hizo una convocatoria abierta a todo el profesorado de la universidad interesado en mejorar asuntos teóricosprácticos de las pedagogías, docencia universitaria y evaluación. Se inscribieron 94 profesores de las distintas facultades, se aspiraba a que el grupo fuera de 50 docentes, sin embargo, la cifra final de inscritos (94) demostró que el asunto de la pedagogía, como un campo de saber, era pertinente porque interroga a la educación y a los educadores, lo cual demuestra un interés conjunto de los maestros por asumir, repensar y hacer actual la pedagogía.

El desarrollo del Seminario-Taller se planteó como un espacio permanente de reflexión sobre los problemas de educación y pedagogía, a partir las reflexiones provocadas por los invitados como Alejandro Álvarez Gallego, Alberto Martínez Boom, Fabio Jurado Valencia, Fernando Vásquez, Daniel Bogoya y Marco Raúl Mejía., todos con altos niveles de formación académica y con una trayectoria investigativa en el campo de la Educación Superior bastante significativa. Se inició así una experiencia intelectual enriquecedora que permitió a los docentes reconocerse en sus lecturas, cuestionamientos y prácticas docentes para reflexionar que el acto pedagógico no termina en el aula, sino que se expande a otros lugares.

De las experiencias pedagógicas propias y de los saberes construidos desde los discursos teóricos, los profesores construyeron paulatinamente reflexiones sobre el oficio del maestro, sobre su rol en las relaciones que se tejen con los estudiantes, la evaluación y el Proyecto Educativo Universitario [PEU] a la luz de un modelo pedagógico que rescate y articule lo multicultural, el diálogo de saberes y la experiencia como insumos para construir desde las pedagogías del sur, identidad del ser universitario en relación a lo expresado en la teleología institucional de la Universidad Surcolombiana. De las grandes reflexiones de los seis Seminarios-Talleres, concluimos, por ejemplo, que el ser docente, primero, es un reconocimiento con el oficio y segundo que no basta con ser un erudito en el conocimiento disciplinar para ser profesor, sino consiste en saber jugar esa triada que de lo cognitivo, tímico y pragmático, expuesto por Greimas y Fontanille (1994), ilustrada por el profesor Fabio Jurado Valencia en su intervención.

En el ejercicio de reflexión sobre la docencia, también se concluyó que el docente tiene una alta dosis de compromiso con la lectura y la escritura, por eso se pensó en la producción escrita desde la reflexión sobre la propia práctica, acompañada de tutorías que dieran lugar a la producción de un artículo para su publicación y divulgación.

No queremos que la Escuela de Formación Pedagógica sea como aquella fábula de Esopo (Siglo VI a. C) denominada "El parto de los montes", gran expectativa genera, mucho se escribe sobre ella, pero al final nuestra acción resulta ser como un melindroso ratón. 
Sin llegar a ser pesimista, considero necesario repensarnos como docentes y cuestionarnos bajo qué autopistas nos movemos, cuál es el éter que guía nuestra función, qué significa ser maestro. Ortega y Gasset insiste en la tarea de la pedagogía: se trata de hacer sentir la necesidad del conocimiento y no creer que la labor del profesor es impartir el conocimiento, como si este se pudiera transmitir de sujeto a sujeto.

Navegamos en este barco, convencidos que es un gran reto que exige de rigurosidad académica, compromiso institucional y sobre todo conciencia de lo necesario que es, como lo han expresado todos los invitados externos, revindicar la pedagogía en la esfera de la Educación Superior y la apertura de espacios en los que se pueda pensar desde el sí y de este modo, ir edificando saberes que sean coherentes con lo plateado por Bernstein "la relación pedagógica también es un procedimiento para constituir una forma particular de conciencia en el otro" (2000).

Este es apenas el inicio de un largo viaje en el que cada día se tejen y entretejen saberes que surgen desde las discusiones académicas serias y argumentadas del profesorado. El oficio de Ser Maestro no fenece con las reflexiones superfluas, sino germinan con las dialécticas de se construyen a partir de las pedagogías.

\section{Bibliografía}

Bernstein, Basil. (2000). Hacia una sociología del discurso pedagógico. Bogotá: Magisterio.

Greimas, Julien y Fontanille, Jacques. (1994). Semiótica de las pasiones: de los estados de cosas a los estados de ánimo. México: Siglo XXI editores.

Ortega y Gasset, J. (1986). Sobre el estudiar y el estudiante. En Inciarte Esteban (ed.). Ortega y Gasset: una educación para la vida. México: SEP. 